\title{
De las playas frías a las playas templadas: la popularización del turismo de ola en España en el siglo $X^{1}$
}

\author{
Carlos LARrinaga \\ Universidad de Granada \\ larrinag67@hotmail.com
}

Recibido: $16 / 03 / 2015$

Aceptado: 03/07/2015

\begin{abstract}
RESUMEN
En el presente artículo se pretende hacer un análisis de cómo a lo largo del siglo XX se produjo un cambio sustancial en la actividad turística europea. En concreto, se dio un cambio de paradigma. El higienismo dio paso a nuevas modas, como el bronceado, y a nuevas prácticas turísticas, que empezaron a poner en valor las playas cálidas del sur de Europa. Además, en la medida en que la situación económica mejoró tras la puesta en marcha del Plan Marshall y el poder adquisitivo de buena parte de los ciudadanos de la Europa occidental empezaron a demandar servicios turísticos, España se convirtió en uno de los principales destinos de sol y playa. Para mediados del siglo XX se había producido ya una verdadera meridionalización del turismo y su democratización o popularización. Un fenómeno que empezó a afectar a los propios españoles desde la década de los sesenta.
\end{abstract}

Palabras clave: turismo, playa, sol, meridionalización, popularización, democratización, España, siglo XX.

\section{From the Cool to the Warm Water Beach: The Popularization of Seaside Tourism in Twentieth-Century Spain}

\begin{abstract}
This article aims to do an analysis of how throughout the 20th century a substantial change occurred in European tourism. In particular, a paradigm shift occurred. Hygienism gave way to new fads, like tanning, and a new tourist practices, which began to give value to the warm beaches of the South of Europe. In addition, to the extent that the economic situation improved after the start of the Marshall Plan and the purchasing power of most of the citizens of Western Europe began to sue tourism services, Spain became one of the main destinations for Sun and beach. Mid-20th century had occurred already a true Southernization of tourism and its democratization, or popularization. A phenomenon that began to affect the own Spanish people since the 1960s.
\end{abstract}

Key words: Tourism, Beach, Sun, Southernization, Popularization, Democraatization, Spain, XX ${ }^{\text {th }}$ Century.

1 Este trabajo se integra en el proyecto de investigación Orígenes, consolidación y evolución del turismo en España (Ministerio d e Economía y Competitividad, HAR2011-23214). Una primera versión muy preliminar de este trabajo fue presentada en el 1er. Congreso Latinoamericano de Historia Económica y en las 4as. Jornadas Uruguayas de Historia Económica (CLADHE I - IV JUHE), celebradas en Montevideo los días 5 - 7 de diciembre de 2007. 


\section{Introducción}

Manteniéndose aún el paradigma higienista que había marcado el turismo de ola del siglo XIX en la fachada atlántica europea, a principios del siglo XX las playas frías de la cornisa cantábrica del norte de España seguían conservando su primacía en el panorama turístico nacional. Sin embargo, a medida que avance el siglo XX y se instale en Europa la nueva moda del bronceado, junto con los propios progresos de la medicina, estas playas frías van a ir poco a poco cediendo paso a las playas del sur del país, caracterizadas por tener unas aguas más cálidas y mayor número de horas de sol. Coincidiendo además con un aumento considerable del nivel de vida de los ciudadanos de la Europa occidental y un aperturismo del régimen franquista, numerosos extranjeros empezaron a frecuentar esos arenales españoles en detrimento de los del mar Cantábrico. Pero, además de esta meridionalización del turismo, es posible hablar igualmente de popularización o democratización, ya que, al establecerse el sistema de vacaciones pagadas, fueron cada más el número de personas que pudieron acceder al veraneo, dirigido, fundamentalmente, hacia el Mediterráneo, la costa andaluza y las Canarias, destinos más baratos y capaces de satisfacer una demanda de características bien distinta a la propia de las playas frías del norte de España.

\section{Pervivencia del paradigma higienista a comienzos del siglo $\mathrm{XX}$}

El higienismo fue una corriente terapéutica promovida por numerosos médicos desde finales del siglo XVIII. En buena medida, fue una consecuencia lógica de los avances producidos con la Revolución Científica y de los postulados racionalistas impuestos por la Ilustración. En puridad, consistía en otorgar una gran influencia e importancia al entorno social y ambiental en la génesis y evolución de las enfermedades. En este sentido, el desarrollo de la Revolución Industrial tuvo unas consecuencias sociales, ambientales y urbanísticas evidentes. De manera que la falta de salubridad de las ciudades en general, pero, sobre todo, de las industriales, y las pésimas condiciones de vida de los obreros fabriles de las mismas favorecieron la expansión de las teorías higienistas y la preocupación entre los médicos por estas cuestiones. No es de extrañar, por tanto, que, en el ámbito de la medicina, los higienistas se ocuparan del medio natural y de su posible conexión con los problemas patológicos del individuo. Imbuidos por ese espíritu racionalista tan característico del siglo de las Luces, diferentes intelectuales y médicos se sintieron más atraídos por las ciencias útiles que por las meras especulaciones. Fue entonces cuando empezaron a publicarse diferentes tratados sobre la bondad de las aguas, tanto minerales como marinas. Sin olvidar, por otro lado, los avances que se produjeron en el campo de la química. Los análisis hechos en las aguas minerales permitieron una nueva valoración de las mismas².

2 BOUZA, Jerónimo (2000): "La difusión de la innovación científica y el desarrollo de la balneoterapia: la incorporación de los procesos de la química", Scripta Nova. Revista Electrónica de Geografía y Ciencias Sociales, 69 (39) (2000), p. 3. 
Estas ideas de los higienitas fueron extendiéndose poco a poco por toda Europa a lo largo de la primera mitad del siglo XIX. Gracias a ellos la confianza en las propiedades salutíferas de las aguas fue cada vez mayor, de manera que la toma de las aguas se fue progresivamente consolidando entre las capas altas de la sociedad. Sin duda, los tratados médicos y las propias medidas adoptadas por el Estado jugaron un papel fundamental en la difusión de la creencia en las propiedades curativas de las aguas termales ${ }^{3}$. En este sentido, las topografías médicas constituyeron un instrumento privilegiado de propagación científica, limitado, como es natural, a los sectores más acomodados de la población. Influenciados por este tipo de obras, tanto la aristocracia como la burguesía adinerada comenzaron a asistir a los centros termales primero y a las localidades balnearias de costa después. La puesta en funcionamiento de algunos centros termales en el siglo XVIII dan fe de ello. De hecho, a partir de ese momento fueron cada vez más los establecimientos de aguas minerales abiertos en España ${ }^{4}$. Así, desde las grandes ciudades españolas, estos pudientes se desplazaban a tomar las aguas. A este respecto, el caso de Madrid podría ser paradigmático. Las deficientes condiciones higiénicas de la ciudad y los fuertes calores que se padecían en verano facilitaban estos traslados. Prueba de ello sería que la propia familia real durante el periodo estival abandonaba su palacio madrileño para soportar mejor la canícula, trasladándose a otras instalaciones palaciegas próximas a la capital. No es extraño, por lo tanto, que desde mediados del siglo XIX, diferentes miembros de la realeza, incluida Isabel II, se desplazaran a la costa cantábrica para disfrutar de sus aguas.

Ahora bien, es muy conocido el desfase existente entre la valoración positiva de las aguas termales y la de las aguas marinas. Al fin y al cabo, sobre las primeras existía una vieja tradición que, cuando menos, se remontaba a la edad antigua y que, en cierta medida, había pervivido en algunos centros termales del centro de Europa, a pesar de las prohibiciones del catolicismo. Por lo que se refiere a las aguas marinas, la situación era bien distinta. Corbin ha hecho especial hincapié en este aspecto. Frente a esa idea de las aguas termales ligadas al placer, el mar se había presentado tradicionalmente como un lugar enigmático, habiéndose mantenido una imagen de miedo y repulsión a lo largo de los siglos. Sólo desde finales del siglo XVII y primeras décadas de la siguiente centuria empezó a ser percibido de forma diferente. El despliegue de lo que en Francia se denominó la teología natural y en Inglaterra la físico-teología tuvo mucho que ver en ello, en la medida en que se empezó a considerar que la belleza de la naturaleza demostraba el poder y la bondad del Creador. Ese temor al mar predominante hasta entonces empezó a ser progresivamente sustituido por el placer de la consideración de un entorno convertido en espectáculo. La actitud respecto del agua marina se transformó y los estudios sobre el poder salutífero del agua del mar se multiplicaron. Si las aguas termales eran bondadosas, también lo eran las marinas.

3 Para el caso español,, véase ALCALDE, Rafael: "La introducción y el desarrollo del higienismo en España durante el siglo XIX. Precursores, continuadores y marco legal de un proyecto científico y social", Scripta Nova. Revista Electrónica de Geografía y Ciencias Sociales, 50 (1999), pp. 1-44.

4 Para una visión general, véase ALONSO, Luis; VILAR, Margarita y LINDOSO, Elvira: El agua bienhechora. El turismo termal en España 1700-1936, Observatorio Nacional del Termalismo, Alhama de Granada, 2012. 
Las aguas y las brisas marinas podían tener propiedades curativas hasta entonces desconocidas, de forma que los médicos empezaron a recomendar los baños de ola. En este sentido, de especial trascendencia resultó la labor del doctor Richard Russell, quien, entusiasmado con el poder curativo de estas aguas, llegó a recomendar que el paciente se bañara en el mar una vez al día, bebiera media pinta de agua marina por la mañana y un vaso al salir del baño y se duchara con agua de mar fría previamente calentada ${ }^{5}$. Sea como fuere, lo cierto es que las vacaciones a la orilla del mar fue una invención inglesa del siglo XVIII que se convirtió en una norma cultural que progresivamente se extendió desde Gran Bretaña a buena parte de la Europa occidental ${ }^{6}$.

Sin llegar a las exageraciones propuestas por Russell, lo cierto es que la consideración beneficiosa del agua del mar estaba ya plenamente arraigada en las capas altas de la sociedad española de mediados del siglo XIX. A la positiva apreciación que se tenía de las aguas minerales siguió una no menor estimación de las aguas del mar. Aunque eso sí, tal como había quedado patente en las topografías médicas, se insistía en que tales aguas debían ser frías. De forma que comenzaron a ponerse de moda los arenales norteños del Cantábrico en el contexto de la nueva valoración de las playas frías de la fachada atlántica europea ${ }^{7}$. Todavía habrían de faltar bastantes décadas para que cobraran protagonismo las playas del Mediterráneo y del sur de España, como más adelante se verá.

Que este paradigma higienista alcanzara de pleno a la Cornisa Cantábrica no es de extrañar si tenemos en cuenta los siguientes elementos. En primer lugar, por la abundancia de aguas minerales y establecimientos termales que en esta zona se levantaron, en especial en el País Vasco y Cantabria ${ }^{8}$. En segundo lugar, porque estamos hablando de una zona costera dentro del océano Atlántico y que, por lo tanto, se vio igualmente afectada por ese paradigma higienista ya mencionado. Es cierto que se dio mucho más tardíamente que en Inglaterra (casi un siglo después) o que en el norte de Europa, pero la costa atlántica española no fue una excepción al fenómeno9 .

\footnotetext{
5 CORBIN, Alain: El territorio del vacio. Occidente y la invención de la playa (1750-1840), Barcelona, Mondadori, 1993, p. 99.

6 WALTON, John K.: "Consuming the Beach. Seaside Resorts and Culture of Tourism in England and Spain from the 1840s to the 1930s", en Shelley BARANOWSKI y Ellen FURLOUGH (eds.): Being Elsewhere. Tourism, Consumer Culture, and Identity in Modern Europe and North America, The University of Michigan Press, Ann Arbor, 2001, p. 272

7 Este tema ha sido tratado en LARRINAGA, Carlos (1999): Actividad económica y cambio estructural en San Sebastián durante la Restauración, 1875-1914, Instituto Dr. Camino de Historia donostiarra, San Sebastián, cap.6. Especialmente interesante resulta asimismo el trabajo de GIL DE ARRIBA, Carmen: Casas para baños de Ola y Balnearios Marítimos en el Litoral Montañés, 1868-1936, Universidad de Cantabria y Fundación Marcelino Botín, Santander, 1992.

8 Véanse, entre otros, LUIS GÓMEZ, Alberto et alii: Aproximación histórica al estudio de los balnearios montañeses (1826-1936), Cámara Oficial de Comercio, Industria y Navegación de Cantabria, Santander, 1989; CAZ, $\mathrm{M}^{\mathrm{a}}$ Rosario del: El agua en el seno de las aguas. La ordenación del espacio balneario en el Cantábrico, Valladolid, Universidad de Valladolid, Valladolid, 2000; URQUÍA, José María: Historia de los balnearios guipuzcoanos, Euskal Medikuntzaren Historia-Mintegia y Medikuntza Historiaren Euskal Elkartea, Bilbao, 1985; y LARRINAGA, Carlos: Balnearios guipuzcoanos, 1776-1901, RSBAP, San Sebastián, 2014.

9 WALTON, John K. \& SMITH, Jenny: "The First Century of Beach Tourism in Spain: San Sebastián d the Playas del Norte from the 1830s to the 1930s", en M. BARKE; J. TOWNER and M. T. NEWTON (eds.): Tourism in Spain. Critical Issues, CAB International, Oxon (U.K.), 1996, p. 36.Véase también VALERO, Alet: "El turismo de playa en España entre 1850 y 1950", en FOURNEAU, Francis y GARCÍA LORCA, Andrés
} 
Tanto en el País Vasco como en Cantabria la cercanía del mar a los centros termales debió incentivar la demanda de baños de ola. Al menos, así parece deducirse del caso guipuzcoano y cántabro ${ }^{10}$. Por último, habría que señalar las mejoras en el transporte terrestre que se dieron entre ambas regiones y Madrid, es decir, entre los puertos del Cantábrico y la capital de España. De hecho, durante el último tercio del siglo XVIII se llevaron a cabo importantes inversiones en carreteras, tratando de mejorar la conexión de Madrid con Santander, Bilbao y la frontera francesa. Décadas más tarde, en plena euforia del ferrocarril, dichos esfuerzos se multiplicaron en forma de caminos de hierro. A este respecto, la línea Madrid-Irún tuvo una importancia capital para el desarrollo turístico del norte peninsular ${ }^{11}$.

Por supuesto, tales elementos eran importantes para generar una oferta turística en esa zona de España, pero por sí solos no bastaban. Era necesario convertir esas potencialidades en un producto turístico, en el sentido dado por Chadefaud. De esta forma, entre 1876 y 1936, se dio el paso de una primera fase de creación del producto (alojamientos, equipamientos, etc.) a una segunda de madurez, caracterizada por su expansión y mayor complejidad ${ }^{12}$. De manera que fueron los sectores más adinerados de la sociedad española los que frecuentaron las estaciones termales, por un lado, y los centros balnearios, por otro. Lógicamente, se trataba de una minoría adinerada con recursos suficientes como para poder permanecer fuera de su residencia habitual durante varios meses. En este sentido, el papel de reyes y príncipes a la hora de promocionar un lugar fue determinante. Son, según la terminología empleada por el profesor Marc Boyer, los llamados stars, que ocupan la posición social más elevada, quienes se adueñan de la invención llevada a cabo por los denominados gate-keepers, la adoptan y la consagran, de suerte que, mediante un fenómeno de "capilaridad social", estos stars son imitados por los grupos sociales más próximos a ellos ${ }^{13}$.

En el caso concreto de San Sebastián parece existir constancia de los primeros bañistas en los años veinte del siglo XIX, es decir, antes de que estallara la Primera Guerra Carlista ${ }^{14}$. Precisamente, los grandes centros de turismo marítimo de la Europa del Norte se constituyeron en el decenio de 1820 a $1830^{15}$. No fue el caso de la capital guipuzcoana, que todavía hubo de esperar algún tiempo. La crisis política vivida en España entre 1833 y 1840 como consecuencia de la guerra civil debió influir en la consolidación de esta localidad como la capital del turismo español de la segunda mitad del siglo XIX. Un hecho relevante en tal proceso fue la presencia en

Miguel (coords.): Desarrollo regional y crisis del turismo en Andalucía, Instituto de Estudios Almerienses, Almería, 1994, pp. 297-329.

10 LARRINAGA, Carlos (1999): Actividad económica..., pp. 469-474, y GIL DE ARRIBA, Carmen: Casas para baños de Ola... En este sentido, francamente revelador resulta la obra de MADRAZO, Francisco de Paula: Una espedicion á Guipuzcoa, en el verano de 1848, Imprenta de G. Gil, Madrid, 1849.

11 BARQUÍN, Rafael: “El Turismo y los primeros ferrocarriles españoles (1855-1914)”, TST, 24, 2013, pp. 110-136.

12 CHADEFAUD, Michel: Aux origines du tourisme dans les pays de l'Adour, Université de Pau, Pau, 1987, p. 20.

13 BOYER, Marc: Le tourisme de l'an 2000, Presses Universitaires de Lyon, Lyon, 2000, pp. 102-106.

14 AGUIRRE, Rafael: El turismo en el País Vasco. Vida e historia, Txertoa, San Sebastián, 1995, pp. 88-89.

15 CORBIN, Alain: El territorio del vacio..., p. 342. Véase asimismo WALTON, John K.: The English Seaside Resort: A social history 1750-1914, Leicester University Press, Leicester, 1983. 
San Sebastián de la reina Isabel II, afectada por una enfermedad cutánea, en el verano de 1845. Siguiendo la terminología de Boyer, se trataba de una auténtica star, cuya presencia habría de ser determinante para la conformación de esa ciudad como destino turístico ${ }^{16}$. En verdad, no era la primera vez que un miembro de la familia real se desplazaba a San Sebastián a tomar las aguas. Un tío suyo, Francisco de Paula Antonio, hermano del rey Fernando VII, ya lo había hecho en 1830 y $1833^{17}$. Sin embargo, la presencia de la soberana daba un tono aún más distinguido a una estación de baños que, a lo largo de los años, se fue convirtiendo en punto de destino del veraneo real, hasta tal punto que fue la reina María Cristina, asidua veraneante en San Sebastián desde 1887, la que decidió construir su propio palacio en la playa de La Concha. Semejante presencia y la mejora ya mencionada en las infraestructuras terrestres (sobre todo, ferrocarriles en el siglo XIX) contribuyeron a hacer de San Sebastián la capital del turismo español ${ }^{18}$.

En cualquier caso, esta ciudad no fue la única playa fría de moda en la España de finales del siglo XIX y de principios del XX. Un rosario de pequeñas localidades costeras guipuzcoanas como Zarauz y más tarde Fuenterrabía fueron ganando cada vez más adeptos, lo mismo que las vizcaínas Portugalete o Algorta. En menor medida, cabría hablar asimismo de otras tantas localidades cántabras o asturianas, destacando, sin duda, entre todas ellas la capital de Cantabria, Santander, que, en el último cuarto del siglo XIX se consolidó como gran centro turístico, generando, gracias en buena medida a la familia Pombo, uno de los espacios turísticos más característicos de España, el de las playas del Sardinero. A él se le añadiría, ya en el siglo XX, reinando Alfonso XIII, la construcción del palacio real de la Magdalena y su cesión al monarca en $1913^{19}$.

\section{Tiempo de ocio y diversión}

$\mathrm{Si}$, por un lado, los tiempos de la toma de baños de ola estaban perfectamente tasados según las indicaciones que hacían los médicos al respecto; por otro, existía un tiempo ocioso que debía ser ocupado. Así, junto al clásico paseo que servía para ver y ser visto o las tertulias en determinados cafés, una opción peculiar de estos balnearios litorales fue la de los casinos. De hecho, un elemento distinguido de toda estación balnearia que se preciase era un establecimiento de semejantes características. El ejemplo más cercano radicaba en Biarritz, cuyo casino de Bellevue había abierto sus puertas en 1858. En San Sebastián, por ejemplo, siguiendo los pasos de su vecina del norte, hubo una primera iniciativa en este sentido ya para 1866, aunque no salió adelante. Las propuestas se sucedieron, pero hasta el 1 de julio de 1887 no abrió sus puertas el Gran Casino de San Sebastián. Años más tarde, el 29 de julio de 1922 se inauguró otro edificio de estas características, el casino del Gran Kursaal, prueba evi-

\footnotetext{
16 Seminario Pintoresco Español, “El veraneo en San Sebastián”, por Ramón de Navarrete, 1848, p. 194.

17 Archivo Municipal de San Sebastián (AMSS), Secc.E, Neg.1, Lib.2015, Exp.2.

18 LARRINAGA, Carlos (1999): Actividad económica..., pp. 505-518.

19 SAZATORNIL, Luis: "Semántica de la ciudad-balneario: el caso del Sardinero de Santander (18401900)", Archivo Español de Arte, 248 (1989), pp 421-434.
} 
dente del auge turístico de la ciudad durante estos años. Sin embargo, tras el decreto del 1 de noviembre de 1924, por el que se prohibían los juegos de azar, este elegante edificio no tuvo más remedio que reorientar su actividad hacia el teatro y desde 1931 también a sala de cine ${ }^{20}$.

De todos modos, además del juego, se organizaron asimismo otras diversiones y actividades con vistas a satisfacer las necesidades de ocio, sobre todo, a consecuencia de la entrada en crisis del paradigma higienista. A este respecto, la elevada mortalidad provocada por las enfermedades contagiosas empezó a poner en entredicho este paradigma. En concreto, la persistencia de la fiebre amarilla y del cólera, que asolaron el continente europeo durante todo el siglo XIX, demostró que las teorías existentes sobre las enfermedades contagiosas eran inadecuadas y las medidas profilácticas propuestas ineficaces. Pero no sólo eso, ya que los nuevos avances de la medicina restaron valor a las creencias curativas de las aguas. Sobre todo, los adelantos producidos en bacteriología e inmunología, donde los descubrimientos de Pasteur y Koch pusieron en entredicho la capacidad curativa de la balnearioterapia ${ }^{21}$. Tal es así que desde comienzos del siglo XX se observa la cada vez menor importancia de los establecimientos de baños termales.

En semejantes circunstancias, y cuando el mito de las funciones salutíferas empezaba a caer, no es extraño que los centros balnearios del litoral comenzaran a reconducir su orientación hacia la diversión y el ocio ${ }^{22}$. El agua de mar podía ser utilizada para otros usos más allá de las terapéuticos, ahora puestos en solfa. En efecto, estas aguas ofrecían unas posibilidades lúdicas hasta ahora sin explorar. Posibilidades que, acompañadas de una buena oferta de ocio, podían reconvertir a las antiguas estaciones balnearias en nuevos centros lúdicos. San Sebastián, en este sentido, resultó paradigmática, ya que desde ese momento no cejó en potenciar nuevos divertimentos para la atracción de los turistas. En efecto, las corridas de toros, las regatas, los partidos de pelota y las carreras de caballos, así como los espectáculos culturales tales como el teatro o los conciertos pasaron a formar parte de esta nueva oferta. Tras la prohibición del juego, se potenciaron aún más algunos de estas atracciones: las carreras de caballos y de automóviles, los concursos hípicos o las regatas de traineras. Incluso, las fiestas vascas de septiembre, celebradas por primera vez en 1927 e impregnadas de folklorismo, fueron un intento más para prolongar la estancia de los veraneantes ${ }^{23}$. En semejante quehacer destacaron algunas figuras como José Arana, que se convirtió

20 SADA, Javier M $M^{\mathrm{a}}$ y HERNÁNDEZ, Tomás: Historia de los casinos de San Sebastián, siglos XIX y XX, Nuevo Gran Casino del Kursaal, San Sebastián, 1987, pp.187-224 y RODRÍGUEZ SORONDO, Ma Carmen: Arquitectura Pública en la ciudad de San Sebastián (1913-1922), Grupo Dr. Camino de Historia donostiarra, San Sebastián, 1985, pp. 188-194.

21 MONTSERRAT ZAPATER, Octavio: El balneario de Panticosa (1826-1936), Diputación General de Aragón, Zaragoza, 1998, p. 231.

22 Para una visión general sobre este tema, véase CORBIN, Alain: L'avènement des loisirs, 1850-1960, Aubier, Paris, 1995. Véase también GIL DE ARRIBA, Carmen: "Les vacances du corps. Établissements balnéaires et activités de loisir sur la côte nord de l'Espagne, de 1868 à 1936", Annales de Géographie, 589 (1996), pp 257-278.

23 AGUIRRE, Rafael: El turismo en el País Vasco..., p. 120 y CASTELLS, Luis“La Bella Easo: 18641936", en Miguel ARTOLA (ed.): Historia de Donostia-San Sebastián, Nerea, Hondarribia, 2000, pp. 336338. 
en el gran empresario de espectáculos de la época, de suerte que no sólo se dedicó a organizar corridas de toros durante la temporada estival, sino también al montaje de conciertos de música, circos y partidos de pelota vasca ${ }^{24}$, o Alfredo Laffitte, personaje clave del turismo local del cambio de siglo y uno de los máximos animadores del Sindicato Oficial de Propaganda primero (1903) y del Sindicato de Iniciativa y de Propaganda después (1909) ${ }^{25}$.

Con ser éstas iniciativas importantes y que, sin duda, contribuyeron a alargar la temporada estival en la ciudad, lo cierto es que esta oferta de ocio en San Sebastián se diversificó aún más gracias a los parques de recreo, pensados para entretener a un público básicamente adulto que buscaba lugares para divertirse y relacionarse. Aunque existían antecedentes previos, lo cierto es que en 1896 se inauguró en la localidad inglesa de Blackpool el denominado Blackpool Plesure Beach, primer centro de atracciones permanente europeo de la era contemporánea. A él le siguió el Tibidabo de Barcelona, que abrió sus puertas en 1901, y muy pronto se trasladó la idea a la capital donostiarra. En ese afán de impulsar la diversión mediante la diversificación de la oferta y de seguir ganando turistas en un momento en que las aguas habían perdido el atractivo terapéutico anterior y la clientela no se limitaba a la nobleza y a la alta burguesía, en 1893 la Compañía del Ferrocarril a Ulía solicitó la concesión de una vía férrea con tracción eléctrica para ascender a este promontorio de la ciudad. Las obras comenzaron en septiembre de 1900, practicándose la inauguración el 8 de junio de $1902^{26}$. En realidad, la idea era su puesta en valor como atractivo turístico, llegando a constituir un parque de recreo, en el que sobresalían un restaurante rodeado de jardines frente a una terraza con magníficas vistas sobre la ciudad, el mar y las montañas circundantes, un transbordador que permitía realizar viajes aéreos de un punto a otro del macizo y un pabellón para la práctica del tiro de pichón.

La iniciativa tuvo éxito y en principio las cosas fueron bien para la compañía, pero la apertura del parque del monte Igueldo, en el otro extremo de la capital y con espectaculares vistas sobre la bahía de La Concha, hizo que el número de visitas descendiera notablemente, hasta tal punto que, andando el tiempo, terminaría por desaparecer, al igual que le sucedió a un tercer parque de recreo que se construyó también a principios del siglo XX a las afueras de San Sebastián, en Martutene. En verdad, ni el de Ulía ni el de Martutene pudieron competir con el parque de Igueldo, existente aún hoy en día. Pegado a la ciudad y con las mejores estampas sobre La Concha, en 1911 se constituyó la sociedad anónima "Monte Igueldo" 27 . Se trataba de una empresa de construcción dedicada a la explotación de terrenos en esa zona y a la erección de un funicular que daría acceso a un centro de ocio. Para acceder a este nuevo parque de recreo el funicular fue inaugurado oficialmente en 1912. Pronto se abrió un restaurante con tal éxito que, en las obras de ampliación llevadas a cabo en 1913 y

24 VALERO, Alet: Oriente, playas y castillos. Pratiques, images et politiques touristiques en Espagne entre 1830 et 1928, Tesis doctoral inédita, Universidad de Aix-Marseille I, 1993, pp. 458-459.

25 VALERO, Alet: Oriente, playas y castillos..., p. 445.

26 SADA, Javier Ma: Compañía del tranvía de San Sebastián, 1887-1987, [Compañía del Tranvía de San Sebastián], [San Sebastián], [1987], pp. 155-157, y GÓMEZ BELDARRAIN, Laurentino: San Sebastián. Historia de los parques de recreo a través de la tarjeta postal, Viena Ediciones, Barcelona, 2005, pp. 37-71.

27 Registro Mercantil de Guipúzcoa, Libro 24, fol. 30, Hoja nº 875. 
1914 , se añadieron una sala de espectáculos y un casino ${ }^{28}$. Con semejante oferta y con el atractivo de las vistas, no es extraño que los otros dos parques se sintieran afectados por la merma de visitantes. El auge de Igueldo no disminuyó siquiera cuando se prohibió el juego en tiempos de Primo de Rivera, ya que la animación no decayó al organizarse concurridos bailes en los salones del casino y sesiones de cine en la sala de espectáculos. Con todo, si inicialmente Igueldo no se había concebido como un parque con atracciones a la manera del Tibidabo o Martutene, tras la prohibición del juego, los responsables de la sociedad optaron por esta vía, de manera que en 1926 se abría al público una montaña rusa.

Ahora bien, coincidiendo con esta transformación de la oferta turística que se produjo en San Sebastián en estas primeras décadas del siglo XX, se dio asimismo ese fenómeno de capilaridad social expuesto por Marc Boyer, de manera que la capital guipuzcoana, aunque consiguió mantener su fama de ciudad elegante, vio cómo el nivel social de sus visitantes descendía. Cada vez mayores sectores de la sociedad española podían permitirse un desplazamiento a los centros balnearios de moda. Sin duda, ya no se trataba de aquellos sectores muy adinerados capaces de tirarse largas temporadas fuera de casa en establecimientos de lujo. Era una burguesía menos acomodada que, por mimetismo, empezaba a asomarse al ocio y a la diversión. Qué duda cabe que ese modelo turístico explotado por San Sebastián desde mediados del siglo XIX o por Santander un poco más tarde había entrado en crisis. Más aún, la prohibición del juego y el descenso del tipo de cambio del franco no hicieron sino acentuarla, en la medida en que aquellas familias adineradas que se acercaban al norte con ánimo de divertirse terminaban optando por Biarritz. Incluso, el puritanismo que dominaba la vida social de esos años tampoco ayudó a una ciudad volcada en la diversificación de su oferta de diversión, atrayendo, en cambio, a familias con un nivel económico más modesto. San Sebastián ya no era el centro de recreo exclusivo de las grandes familias que gozaban de poder económico, social o político ${ }^{29}$.

\section{El descubrimiento del sol y los orígenes de la meridionalización del turismo}

En paralelo a lo que se ha dicho, hay que decir también que a partir de principios del siglo XX se empiezan a detectar algunos cambios que van a ser de especial trascendencia para el devenir del turismo europeo en general y español en particular. Desde aproximadamente 1900 se observa un interés nuevo por la natación que va a favorecer a las aguas más templadas ${ }^{30}$. Hasta entonces individuos pertenecientes a la alta sociedad europea se habían desplazado al Midi francés para disfrutar de su cálido invierno, abandonándolo en verano a causa de las altas temperaturas. El caso de la localidad francesa de Sète resulta significativo, pudiendo ser considerada como la primera gran estación balnearia del Mediterráneo en insertarse en el circuito

28 GÓMEZ BELDARRAIN, Laurentino: San Sebastián..., pp. 131-190.

29 GÁRATE, Montserrat y MARTÍN RUDI, Javier: Cien años de la vida económica de San Sebastián (1887-1987), Instituto Dr. Camino de Historia donostiarra, San Sebastián, 1995, pp. 281-286.

30 BOYER, Marc: "El turismo en Europa, de la Edad Moderna al siglo XX", Historia Contemporánea, 25 (2002), p. 25. 
internacional. Principalmente, fue el destino de aquellos aristócratas ingleses que se instalaban en la ciudad unos siete meses al año, de octubre a abril. En este caso habría que hablar de invernantes. No se trataba todavía de un modelo alternativo al de las playas frías, sino complementario. Afectados en muchos casos por enfermedades pulmonares, se desplazaban al Mediterráneo para disfrutar de un invierno menos riguroso que el de Gran Bretaña. En este sentido, la edad de oro del Midi se produjo en la segunda mitad del siglo XIX ${ }^{31}$. Fue entonces cuando localidades como Cannes, Niza o Montecarlo empezaron a ser frecuentadas por estos nuevos turistas de invierno que se hicieron construir grandiosas villas. Para entonces, además, los médicos de Montpellier hablaban ya de los efectos beneficiosos de los rayos de sol ${ }^{32}$.

Ahora bien, a causa del fuerte calor que hacía en esta zona durante el verano, el desarrollo turístico de la Costa Azul francesa fue lento y tardío. En efecto, antes de 1925 los inicios fueron muy modestos: Bandol hacia 1881 y más tarde La Ciotat e Hyères-Plage. A continuación Cannes, donde ya un limitado número de hoteles empezó a abrir en verano, y el cabo de Antibes, donde Antonio Sella fue el primer gran hotelero que creyó en las posibilidades de una sesión balnearia de verano. En definitiva, avances muy claros desde el comienzo de la centuria que se pueden seguir a través de las guías de la época. De esta forma se pasó de una decena de lugares citados hacia 1900 a una treintena hacia 1925. Evidentemente, estaríamos hablando de pequeñas estaciones con uno o dos hoteles ${ }^{33}$.

Precisamente, a partir de 1925 la aparición de Juan-les-Pins fue un auténtico éxito. Con el nacimiento de esta estación balnearia el turismo a orillas del Mediterráneo tomó, sin duda, carta de naturaleza. Con anterioridad a esa fecha este nombre jamás se mencionaba, pero en algunos años la Pinède cobró una importancia sin precedentes. Las guías comenzaron a hablar de ella más que de ninguna otra playa mediterránea, sin que tuviera aún ningún rival. El lugar, además de poseer unas espléndidas vistas, contaba con una decena de hoteles, entre los que sobresalía, sin duda, el "Provençal", y un casino. Descubierto por algunos americanos, entre 1925 y 1927 alcanzó un importante desarrollo gracias a los Gould, millonarios instalados en París durante temporadas. Su grupo, a través de una sociedad inmobiliaria, consiguió juntar capitales considerables para impulsar la estación. Una estación que sedujo rápidamente, debido a los atractivos que tenía. Artistas de renombre internacional animaban las interminables noches en la que se dieron cita reyes (los de Grecia), príncipes (el de Windsor), escritores y muchas estrellas de Hollywood. Ahora bien, Juan-les-Pins no fue el único caso. También podemos hablar de Megève, promocionado en este caso por los Rothschild. En definitiva, nuevas estaciones balnearias muy ligadas a la fiesta estival promovida por los americanos. Por otro lado, tampoco debemos olvidar que al final de la Primera Guerra Mundial, muchos soldados estadounidenses, heridos o enfermos, se habían alojado en hoteles del sur de Francia, comprobando que el verano mediterráneo era más llevadero comparándolo con los de los climas semi-

31 BOYER, Marc: L'hiver dans le Midi. L'invention de la Côte d'Azur XVIIIe-XXIe siècle, L'Harmattan, Paris, 2009.

32 BATTILANI, Patrizia: Vacanze di pochi, vacanze di tutti. L'evoluzione del turismo europeo, il Mulino, Bologna, 2001, pp. 111-113.

33 BOYER, Marc: "El turismo en Europa..., p. 26. 
continentales o sub-tropicales. Salvo los que vivían en la región del Pacífico, los norteamericanos venían padeciendo estíos de muchísimo calor. En comparación, el clima del Mediterráneo era más llevadero ${ }^{34}$.

Se iniciaba así una nueva etapa dentro de la historia del turismo en la que un nuevo paradigma basado en el sol y las playas templadas en sustitución de las frías comenzó a implantarse poco a poco. Por supuesto, en este lento proceso de meridionalización del turismo la costa mediterránea pasó a desempeñar un papel fundamental. Poco a poco se fue imponiendo la atribución de una función benéfica al sol. Hasta entonces lo normal era vestirse rigurosamente protegidos del sol mediante sombreros y trajes largos. Cuando la consideración sobre el sol empezó a cambiar, el nuevo paradigma recién mencionado comenzó a abrirse paso progresivamente. En concreto, fue en los años veinte y treinta cuando nació el mito del bronceado, siendo las playas del sur las que contaban con una ventaja comparativa evidente. Al mismo tiempo, en un momento en que, como ya se ha dicho, se habían cuestionado las cualidades terapéuticas de las aguas, la función del baño cambió, pasando a formar parte de la actividad lúdica ligada ahora a las playas. Por supuesto, semejante descubrimiento del sol revolucionó el mapa del turismo balneario y de las estaciones, iniciándose una auténtica competencia entre las playas del Norte y las del Sur ${ }^{35}$.

Lógicamente, España no fue ajena a este proceso que acabamos de describir, de forma que entre finales del siglo XIX y principios del XX se empezaron a poner en valor algunas localidades y playas de su costa mediterránea con vistas, inicialmente, a convertirlas en estaciones de invierno ${ }^{36}$. En este sentido, el caso de Málaga resulta ciertamente interesante. Tras el periodo de crecimiento que había experimentado la economía malagueña en los dos primeros tercios del siglo XIX, a partir de 1870 la ciudad entró en franca decadencia, debido a la crisis agraria como consecuencia de la irrupción de la filoxera en 1878 y a la des-capitalización que se produjo en los sectores industrial y comercial. Precisamente, en tales circunstancias fueron numerosas las voces de la sociedad malagueña que se alzaron a favor de convertir la capital andaluza en un destino turístico. Esta localidad contaba para ello con un clima muy benigno en invierno y, de hecho, en un artículo publicado en 1872 por el ingeniero José María de Sancha en "El Avisador Malagueño" a propósito de la feria de la ciudad se mencionaban ya las grandes posibilidades de explotación de su clima. Unos años más tarde, en 1880, el médico Vicente Martínez Montes insistía en su obra Del clima de Málaga en los aspectos beneficiosos de éste desde el punto de vista medicinal, comparándola

34 BOYER, Marc: "El turismo en Europa..., p. 26-27.

35 BATTILANI, Patrizia: Vacanze di pochi..., pp. 115-116. Una visión de conjunto en el caso español la tenemos en CIRER, Joan Carles: "Spain's new coastal destinations. 1883-1936: The mainstray of the development of tourism before the Second World War", Annals of Tourism Research, 45 (2014), pp. 18-29. A modo de comparación, para el caso de Italia, véase PIERUCCI, Paola: 2Bagni di mare, bagni di sole e altro: le strutture balneari in Italia tra otto e novecento", en Carlos BARCIELA, Carles MANERA, Ramon MOLINA y Antonio di VITTORIO (eds.): La evolución de la industria turística en España e Italia, Institut Balear d'Economia, Palma, pp. 271-314. Para un estudio de caso, véase, por ejemplo, lo acontecido en la región italiana de Liguria, muy bien estudiada en: ZANINI, Andrea: Un secolo di turismo in Liguria, FrancoAngeli, Milano, 2012.

36 TATJER, Mercedes: "En los orígenes del turismo litoral: los baños de mar y los balnearios marítimos en Cataluña”, Scripta Nova, Revista Electrónica de Geografia y Ciencias Sociales, XIII (296) (2009). 
con otras estaciones de invierno como Nápoles, Roma, Pisa, Niza, Madeira y Argel. Por su parte, el catedrático de instituto Pedro Marcolains San Juan publicaba en 1893 una obra con el significativo título de Medios prácticos para convertir a Málaga en la mejor estación de Invierno de Europa. Más aún, en una memoria escrita por Luis de León en 1894 se hablaba ya de Málaga, estación de invierno. Al año siguiente, José Ramos Power, personalidad clave en todo este proceso, publicaba asimismo un trabajo titulado Málaga, estación de invierno. Por y para ella ${ }^{37}$.

En definitiva, estaríamos hablando de toda una reflexión por parte de personajes cualificados de la vida social malagueña de finales del siglo XIX que veían en el turismo de invierno, en un contexto de crisis económica, una nueva posibilidad para Málaga, tal como había sucedido en otras zonas del sur de Europa. No obstante, eran propuestas inconexas que no terminarían por cuajar hasta la fundación de la Sociedad Propagandista del Clima y Embellecimiento de Málaga, en cuyo nacimiento jugó un papel destacado un grupo de extranjeros residentes en la ciudad, en especial los cónsules y, sobre todo, el de Inglaterra, Alexander Finn. De esta guisa, el Reglamento de la SPCyEM se aprobó el 11 de diciembre de 1897. Con la creación de esta sociedad, sus impulsores lo que pretendían era llevar a cabo una verdadera dirección y coordinación del turismo en Málaga, para lo cual orientaron sus actividades en tres direcciones, a saber: la propaganda del clima, el embellecimiento urbanístico y la higiene pública y los festejos y actividades culturales, de forma que desde su fundación la SPCyEM fue incrementando considerablemente el cupo de actividades que desarrollaba, consiguiendo llegar con sus iniciativas a los más amplios quehaceres de la vida pública local ${ }^{38}$. Ahora bien, las cosas debieron ir lentas, ya que, según un informe fechado en 1911 y elaborado por el cónsul de Francia en Málaga, Jacques Chaumié, la ciudad seguía padeciendo grandes carencias en materia turística ${ }^{39}$. De manera que, si a finales del siglo XIX y principios del XX se había tratado de hacer de Málaga una ciudad de invierno, en los años veinte y en los treinta se empezó a insistir en la bondad no sólo de sus playas, sino también de las de otras localidades de la provincia. La posibilidad de empezar a veranear en Málaga empezaba a coger cada vez más fuerza ${ }^{40}$.

Otro caso especialmente interesante resulta ser el de Alicante. En esta ocasión, las favorables circunstancias económicas que propició el comercio del vino hacia Francia, cuyos viñedos habían sido atacados por la filoxera, hicieron de esta localidad levantina una residencia de invierno para las familias acomodadas de la misma provincia, a las que pronto se añadieron las provenientes de Madrid y del norte del

37 ARCAS CUBERO, Fernando y GARCÍA SÁNCHEZ, Antonio: "Los orígenes del turismo malagueño: la Sociedad Propagandista del Clima y Embellecimiento de Málaga”, Jábega, 32 (1980), pp. $42-44$ y PELLEJERO, Carmelo: "El turismo como alternativa económica en la Málaga de principios de siglo: Informe del Cónsul de Francia", Revista de Estudios Regionales, 42 (1995), pp. 297-303.

38 ARCAS CUBERO, Fernando y GARCÍA SÁNCHEZ, Antonio: "Los orígenes del turismo malagueño...", pp. 46 y 48.

39 PELLEJERO, Carmelo: "El turismo como alternativa económica...".

40 PELlEJERO, Carmelo: "Turismo y Economía en la Málaga del siglo XX", Revista de Historia Industrial, 29 (2005), p. 89. 
país $^{41}$. En este sentido, no hay que olvidar que, teniendo en cuenta lo que estaba sucediendo en la vecina Costa Azul, la Administración y los prohombres locales vieron en el clima de la ciudad una hipotética fuente de riqueza. Así, la preocupación oficial cristalizó en una serie de concursos a los que se presentaron memorias escritas por médicos e higienistas en las que latía la idea de convertir a Alicante en una estación invernal. En este sentido, la campaña desarrollada por "El Imparcial" en 1879 y 1880 resulta ser ciertamente significativa. En fin, estaríamos ante una importante labor promocional de las excelencias del clima local que culminó en la creación de la Comisión para la propaganda del Clima de Alicante. Un clima especialmente apto para los tuberculosos, los que padecían de escrófula y, en general, para todos los afectados por procesos crónicos bronco-pulmonares, así como para los que tenían perturbaciones neuróticas ${ }^{42}$. Orientándose hacia una clientela de lujo, se aspiraba a hacer de la ciudad el punto de cita de la aristocracia europea durante el invierno, algo que, en verdad, no se consiguió por una auténtica falta de empeño en la acción y porque la propia dinámica del veraneo propició la concentración de los esfuerzos en el auge de la temporada de baños. A este respecto, no debemos olvidar que las primeras constataciones de establecimientos balnearios de la costa alicantina datan del siglo XIX, destacando especialmente la propia capital y Torrevieja ${ }^{43}$.

Por último, un tercer ejemplo es el de Mallorca, en las islas Baleares ${ }^{44}$. Echando mano a la terminología de Marc Boyer, fueron fundamentalmente los escritores y pintores los auténticos gate-keepers de la puesta en valor de este destino turístico ya en el siglo XIX, aunque hubo que esperar a los últimos años de esa centuria y a los primeros del XX para ver nacer una primera industria turística mallorquina ${ }^{45}$. En efecto, el 9 de febrero de 1903 se inauguraba el Gran Hotel, siguiendo el modelo de los hoteles Ritz. Poco después, a finales de 1905 se fundó el Fomento del Turismo de Mallorca, una asociación privada cuya principal finalidad era la de facilitar la llegada de turistas a la isla. Para ello, el Fomento se dedicó a tareas como la de mejorar la infraestructura turística, atender y proteger los intereses de los visitantes, hacer campañas de promoción y proporcionar una estancia entretenida. A partir de ese momento se intensificó la labor propagandística de promoción de un turismo de invierno en la isla, además de impulsar todo lo que tenía que ver con la cultura de la misma, en especial con la puesta en valor de sus monumentos ${ }^{46}$

\footnotetext{
41 VERA REBOLLO, José Fernando: "Las condiciones climáticas y marítimas como factores de localización del turismo histórico alicantino", Investigaciones Geográficas, 3 (1983), p. 166.

42 VERA REBOLLO, José Fernando: "Las condiciones climáticas...", pp. 162, 164-165 y 174 (nota 5).

43 VERA REBOLLO, José Fernando: "Las condiciones climáticas...", pp. 166 y ss.

44 CIRER, Joan Carles: La invenció del turisme de masses a Mallorca, Documenta Balear, Palma, 2009.

45 CIRER, Joan Carles: "The beginnings of tourism in Majorca. 1837-1914", Annals of Tourism Research, 39-4 (2012), pp. 1779-1796.

46 VIVES REUS, Antoni: Historia del Fomento del Turismo de Mallorca (1905-2005), Foment del Turisme de Mallorca, Palma, 2005, pp. 24-30, 36, 45, 60-74.
} 


\section{La consolidación del modelo turístico de sol y playa}

Aunque es verdad que todavía en los años treinta las playas frías del norte peninsular seguían estando de moda entre buena parte de la sociedad española de la época, lo cierto es que los arenales cálidos del Mediterráneo respondían a una demanda cada vez mayor. Las cifras eran aún humildes, pero apuntaban una tendencia que se confirmaría años más tarde. Por ejemplo, pese a que no se disponen de datos fiables para la presencia de turistas, nacionales y extranjeros, en las Islas Baleares para los años comprendidos entre 1905 y 1949, se ha estimado una cifra aproximada de 900.000 visitantes para todo el periodo, lo que daría una media de $18.000 \mathrm{al}$ año ${ }^{47}$. Cantidad modesta, ciertamente, en comparación con lo que sucedió sólo unas décadas más tarde, aunque reveladora. En este sentido, no debemos olvidar que en 1931 visitaron España 276.300 personas procedentes del extranjero, siendo algo menos, 275.611, en $1934^{48}$. Frente a destinos como Italia, Suiza, Alemania o Francia, España no era aún una potencia turística. Al contrario, lo podemos definir como un país rezagado en esta materia ${ }^{49}$. Más aún, tampoco ayudó el hecho de que en plena temporada de baños, en julio de 1936, estallara la Guerra Civil, prolongándose hasta 1939, año en que, como se sabe, comenzó la Segunda Guerra Mundial. No corrían buenos tiempos para la actividad turística.

\begin{tabular}{|l|l|}
\hline Italia & 3,9 \\
Alemania & 1,7 \\
Suiza & 1,5 \\
Austria & 1,2 \\
Francia & 1,0 \\
España* & 0,2 \\
\hline \multicolumn{2}{|c|}{ * Media 1931-1934 } \\
\hline
\end{tabular}

Cuadro 1. Afluencia de visitantes en varios países europeos en 1938 (en millones). Fuente: FERNÁNDEZ FUSTER, Luis: Historia general del turismo de masas, Alianza, Madrid,1991, pp. 231 y 622.

Hubo que esperar, por tanto, a que la situación política, económica y social internacional se fuera normalizando para ver emerger a España como nueva potencia turística mundial. La clave estuvo, desde el punto de vista que nos ocupa, en el triunfo de un nuevo paradigma turístico basado en el sol y la playa. De ahí que los países del sur de Europa fueran los más beneficiados de esta nueva demanda turística, siendo España uno de los países más favorecidos por este importante flujo turístico. Las causas del fuerte incremento de turistas fuera de sus países se puede explicar a la luz de hechos tales como la progresiva disminución de restricciones sobre los cambios de

47 VIVES REUS, Antoni: Historia del Fomento del Turismo..., p. 423.

48 PELLEJERO, Carmelo: “Antecedentes históricos del turismo en España: de la Comisión Nacional al Ministerio de Información y Turismo, 1900-1950”, en Carmelo PELLEJERO (dir.): Historia de la economía del turismo en España, Civitas, Madrid, 1999, p. 72.

49 VALLEJO, Rafael: De país turístico rezagado a potencia turística. El turismo en la España de Franco, Documento de Trabajo, Asociación Española de Historia Económica, Madrid, 2014. 
divisas y los viajes, que habían predominado en los años inmediatamente posteriores a la Segunda Guerra Mundial; las mejoras acaecidas en los medios de transporte, automovilístico y aéreo especialmente; la generalización de las vacaciones pagadas; el crecimiento económico vivido en buena parte de los países más desarrollados tras la puesta en marcha del Plan Marshall; el aumento de las rentas personales de sectores cada vez más amplios de la población y la mayor disposición de tiempo libre. Todos estos factores hicieron que, en general, internacionalmente el número de turistas se incrementara sensiblemente. No obstante, es necesario señalar algunas de las causas que convirtieron a la España de esos años en uno de los destinos preferidos de tales turistas. Podría hablarse, en efecto, de su cercanía respecto de los países emisores de turistas, de la devaluación de la peseta de 1959 y de la política que mantuvo los precios turísticos españoles a unos niveles muy competitivos en comparación con otros mercados de una morfología física y climática bastante diferente a la de los países de origen de los turistas, de un rico patrimonio artístico y cultural, del descubrimiento de España por los promotores internacionales de turismo como destino ideal para desarrollar un negocio con inmejorables perspectivas y de la existencia de una Administración consciente de la importancia que podía tener el turismo como una de las principales fuentes de obtención de divisas con vistas a equilibrar su balanza de pagos, tal como más adelante se mencionará ${ }^{50}$.

Gracias a todo este cúmulo de factores, tanto internacionales, como nacionales, España se convertía en destino privilegiado de eso que se ha dado en llamar turismo de masas por haber dejado ya de ser una práctica social exclusiva de unos $\operatorname{pocos}^{51}$. En otras palabras, el turismo se transformó de un bien de lujo a un bien casi de primera necesidad, al que a partir de determinado nivel de renta empezaba a ser difícil renunciar $^{52}$. En expresión feliz de Patrizia Battilani (2001), se había pasado de "vacanze di pochi" a "vacanze di tutti" y España encajaba perfectamente en esta nueva demanda social del turismo ${ }^{53}$. Las cifras a este respecto en España son esclarecedoras, convirtiéndose ya en la década de los sesenta en una auténtica potencia turística, cuando, en realidad, a principios del siglo XX, había partido de una posición más bien rezagada.

50 PELLEJERO, Carmelo: "La política turística en la España del siglo XX: una visión general”, Historia Contemporánea, 25 (2002), pp. 242-243; MORENO GARRIDO, Ana: Historia del turismo en España en el siglo XX, Síntesis, Madrid, 2007, parte 3; PACK, Sasha, D.: La invasión pacífica. Los turistas y la España de Franco, Turner, Madrid., 2009; VALLEJO, Rafael: "Turismo y desarrollo económico en España durante el franquismo, 1939-1975", Revista de la Historia de la Economía y de la Empresa, 7 (2013), pp. 423-452; y VALLEJO, Rafael: De país turístico rezagado...

51 FERNÁNDEZ FUSTER, Luis: Historia general del turismo de masas, Alianza, Madrid, 1991. Una visión general para la Europa del Mediterráneo, la encontramos en SEGRETO, Luciano; MANERA, Carles \& POHL, Manfred (eds.): Europe at seaside. The economic history of mass tourism in the Mediterranean, Berghahn Books, New York, 2009.

52 VALLEJO, Rafael: "Economía e historia del turismo español del siglo XX", Historia Contemporánea, 25 (2002), p. 204.

53 A modo de comparación, véase el caso italiano en BERRINO, Annunziata: Storia del turismo in Italia, il Mulino, Bologna, 2011. 


\begin{tabular}{|c|l|l|l|l|l|}
\hline AÑOS & ENTRADAS & No ÍNDICES $^{\circ}$ & AÑOS & ENTRADAS & N $^{\circ}$ ÍNDICES \\
\hline 1950 & 749.544 & 100 & 1963 & 10.931 .626 & 1.458 \\
1951 & 1.263 .197 & 169 & 1964 & 14.102 .888 & 1.882 \\
1952 & 1.485 .248 & 198 & 1965 & 14.251 .428 & 1.901 \\
1953 & 1.710 .273 & 228 & 1966 & 17.251 .746 & 2.302 \\
1954 & 1.952 .266 & 260 & 1967 & 17.858 .555 & 2.383 \\
1955 & 2.522 .402 & 337 & 1968 & 19.183 .973 & 2.449 \\
1056 & 2.728 .002 & 364 & 1969 & 21.682 .091 & 2.893 \\
1957 & 3.187 .015 & 425 & 1970 & 24.105 .312 & 3.216 \\
1958 & 3.593 .867 & 479 & 1971 & 26.758 .156 & 3.570 \\
1959 & 4.194 .686 & 560 & 1972 & 32.506 .591 & 4.337 \\
1960 & 6.113 .255 & 816 & 1973 & 34.558 .943 & 4.611 \\
1961 & 7.455 .262 & 995 & 1974 & 30.342 .871 & 4.048 \\
1962 & 8.668 .722 & 1.157 & 1975 & 30.122 .478 & 4.019 \\
\hline
\end{tabular}

Cuadro 2. Visitantes procedentes del extranjero que entraron en España durante el periodo 1950-1975.

Fuente: FIGUEROLA, Manuel: "La transformación del turismo en un fenómeno de masas. La planificación indicativa (1950-1974)", en Carmelo PELLEJERO (dir.): Historia de la economía del turismo en España, Civitas, Madrid, 1999,p. 82.

Sin lugar a dudas, el régimen franquista supo ver perfectamente las potencialidades que la actividad turística tenía para una economía tan atrasada como la española y no dudó en aprovecharlas. De hecho, una de las características más notables de la economía española de la segunda etapa del franquismo fue el boom que el turismo experimentó. Pues si durante la década de 1950 la llegada de visitantes procedentes del extranjero fue aumentando poco a poco, a partir de 1960 las cifras se dispararon. Precisamente, el rasgo sustantivo del periodo comprendido entre 1951 (creación del Ministerio de Información y Turismo) y 1962 fue el descubrimiento del turismo por parte de algunos decisores públicos ${ }^{54}$. Fue, sin embargo, a partir de la aprobación del Plan de Estabilización de la economía española de 1959 cuando el turismo fue teniendo un peso cada vez más notable en la economía del país. Hay que recordar que con la política autárquica impuesta por la dictadura tras la Guerra Civil la economía española llegó al colapso. De ahí que el Plan de Estabilización tuviera como prioridad la corrección del déficit de la balanza exterior. Además de este objetivo a corto plazo, que precisaba de medidas monetarias, fiscales y cambiarias, el programa buscaba crear las condiciones adecuadas para que no reapareciera la crisis de pagos. Para alcanzar semejante objetivo, de largo plazo, hacían falta reformas estructurales muy profundas y variadas, que pasaban fundamentalmente por la desregulación y la liberalización internas y externas de la economía. Por eso, el del 1959 era a la vez un plan de estabilización y un plan de liberalización. Un Plan cuyos resultados fueron espectaculares, sobre todo, en lo referente a las cuentas exteriores. Ciertamente, las reservas comenzaron a aumentar desde el primer momento gracias a la repatriación de capitales y a la expansión de la exportación de bienes y servicios, fundamental-

54 VELASCO, María: La política turística. Gobierno y Administración Turística en España (1952-2004), Tirant lo Blanch, Valencia, 2004, p. 137. 
mente a través del turismo. Al poco tiempo se sumarían también las inversiones de capital extranjero ${ }^{55}$. Pues bien, el papel del turismo en esta nueva fase de la economía española fue determinante.

Con el Plan de Estabilización en marcha, las autoridades del régimen apostaron claramente por la industrialización del país. Pero ello implicaba un incremento de las importaciones, las cuales, para ser financiadas, exigían asimismo un aumento de las exportaciones. El problema radicó en que éstas siempre fueron menores que las importaciones, por lo que el crecimiento español de todos estos años estuvo desequilibrado. España, pues, se industrializó, aunque mediante un constante déficit en la balanza de mercancías. El cual se cubrió en parte gracias a las divisas obtenidas por la venta de servicios turísticos. De esta forma, la actividad turística fue desempañando cada año un papel equilibrador básico, ya que la cobertura de las importaciones por el turismo pasó de un valor de 8,97\% en 1955 al 23,38\% en 1960, al 35,47\% en 1971 y al $35,92 \%$ en $1976^{56}$.

Desde el punto de vista del turismo, el Plan de Estabilización tuvo un impacto muy notable, ya que fijó el tipo de cambio del dólar en 60 pesetas, cuando lo estaba en 42, pudiéndose considerar ésta una de las medidas fundamentales para explicar el fuerte aumento de la demanda turística extranjera a partir de estos años, sobre todo, de turismo de sol y playa, como ya se ha dicho ${ }^{57}$. Semejante devaluación suponía una disminución muy considerable en los costes de las vacaciones. Pero, además, el Plan de Estabilización sancionaba la política de control de precios turísticos llevada a cabo por el gobierno. Es decir, que la Administración fijaría el coste mínimo y máximo por habitación según la categoría del establecimiento y mediante un sistema de inspectores. Con ello se pretendía, evidentemente, mantener la competitividad del sector a nivel internacional y evitar los abusos a los consumidores ${ }^{58}$. Esta contención de los precios, y en un contexto de depreciación de la peseta, contribuyó necesariamente a disparar las cifras de visitantes extranjeros en España, tal como se aprecia en el cuadro 2. Gracias a ese proceso de mimetismo o capilarización descrito por Boyer (2002), las clases medias y trabajadoras de los diferentes países de la Europa occidental lograron acceder a un bien, las vacaciones en el extranjero, que no hacía mucho había sido considerado de lujo ${ }^{59}$.

55 CARRERAS, Albert y TAFUNELL, Xavier: Historia económica dela España contemporánea, Crítica, Barcelona, 2004, pp. 327 y 329.

56 FIGUEROLA, Manuel: "La transformación del turismo en un fenómeno de masas. La planificación indicativa (1950-1974)", en Carmelo PELLEJERO (dir.): Historia de la economía del turismo en España, Civitas, Madrid, 1999, pp. 98-99. Esta relación de dependencia ha sido bien explicada por ESTEVE SECALL, Rafael y FUENTES GARCÍA, Rafael: Economía, instituciones e historia del turismo en España, Pirámide, Madrid, 2000, pp. 149-152.

57 Aun no tratándose de un libro académico, resulta de interés BRAY, Roger \& RAITZ, Vladimir (2001): Flight to the Sun. The Story of the Holiday Revolution, Continuum, London \& New York. Véase también PACK, Sasha, D.: La invasión pacifica..., pp. 155-159.

58 VELASCO, María: La política turística..., pp. 126-127. Para esta cuestión y su relación con los touroperadores, véase también BOTE, Venancio \& SINCLAIR, M. Thea: "Tourism Demand and Supply in Spain", in M. BARKE; J. TOWNER \& M. T. NEWTON (eds.): Tourism in Spain: critical issues, CAB International, Oxon, 1996, pp. 78-83.

59 BOTE, Venancio \& SINCLAIR, M. Thea: “Tourism Demand...", p. 66. Para el caso británico, resulta de interés el trabajo de COOPER, Chris: "Parameters and indicators of the decline of the British seaside resort", 
Los numerosos kilómetros de playa del litoral español y el clima de buena parte de sus regiones podían responder perfectamente a las necesidades de esos turistas procedentes del norte y del centro de Europa que, acostumbrados a largos y fríos inviernos, buscaban en el sur del continente nuevas experiencias y sensaciones. Además, los avances en los medios de transporte (avión, sobre todo) y en las formas de viajar (agencias especializadas, paquetes vacacionales, etc.) no hicieron sino favorecer estos desplazamientos desde esos países emisores a España. De hecho, el patrón turístico diseñado en la década de los sesenta se fundó, como ya se ha dicho, en el sol y en la playa, afianzándose este modelo desde principios de la década de 1970. Modelo concentrado no sólo en su oferta, condensada en seis provincias (Gerona, Baleares, Alicante, Málaga y las dos provincias canarias), que representaban entre el 80 y el $85 \%$ de las pernoctaciones de extranjeros, sino también en su demanda, al suponer el origen europeo entre el 85 y el $90 \%$ del gasto ${ }^{60}$. Sin duda, el rasgo más característico de esos años hasta la crisis de los setenta fue el triunfalismo del desarrollo turístico, apoyado en el crecimiento sostenido tanto de la llegada de turistas, como de la oferta turística del país. Se pretendía impulsar un turismo masivo como garantía de estabilidad de la economía española ${ }^{61}$. No es de extrañar, por tanto, que el impacto del turismo en el PIB español pasara del 2,3\% en 1950 al 9,01\% en $1974^{62}$.

\begin{tabular}{|l|c|}
\hline Productos & $\%$ \\
\hline Sol y playa & 73,3 \\
Naturaleza & 2,4 \\
Cultura y diversiones & 10,0 \\
Otros & 14,3 \\
\hline
\end{tabular}

Cuadro 3. Estructura de la demanda turística en España en 1978.

Fuente: VALLEJO, Rafael: "Economía e historia del turismo español del siglo XX", Historia Contemporánea, 25 (2002), p. 217.

Ahora bien, el relumbrón de las cifras referidas a los visitantes procedentes del extranjero no puede hacernos olvidar el dato de la progresiva incorporación de los españoles al consumo turístico. De hecho, a principios del siglo XX quienes veraneaban en España eran fundamentalmente nacionales. Es verdad que desde finales de la década de 1950 la riada de turistas extranjeros minimizó la importancia del turismo interior, relegado a una fracción menor respecto al total de turistas, pero no es menos cierto que la entidad del turismo nacional fue poco a poco en aumento, en especial, a partir de la bonanza económica de la que empezó a disfrutar el país en la década de los sesenta. En este sentido, basta recordar que en 1967 el consumo turístico en España de los residentes supuso un $22,5 \%$ del total, para, a partir de ese momento,

in G. SHAW \& A. WILLIAMS (eds.): The rise and fall of British coastal resorts, Mansell, London, 1997, pp. 79-101.

60 VASALLO, Ignacio: “Crisis y consolidación, 1972-1982”, en Fernando BAYÓN (dir.): 50 años del turismo español. Un análisis histórico y estructural, Centro de Estudios Ramón Areces, Madrid, 1999, p.106.

61 VELASCO, María: La política turística..., pp. 189-190.

62 FIGUEROLA, Manuel: "La transformación del turismo...", p. 97. 
aumentar inexorablemente ${ }^{63}$. En efecto, desde principios de la década de 1970 se ha producido un continuo aumento de la tasa de vacaciones de los españoles. Así, a principios de los años ochenta se situaba ya en torno al 30\%, incrementándose en años sucesivos, tal como se aprecia en el cuadro 4. Evidentemente, el incremento que la tasa de vacaciones experimentó durante los últimos años del siglo pasado indica una generalización de las mismas en la sociedad española, aunque con fluctuaciones evidentes en función de las distintas coyunturas económicas por las que ha atravesado el país ${ }^{64}$.

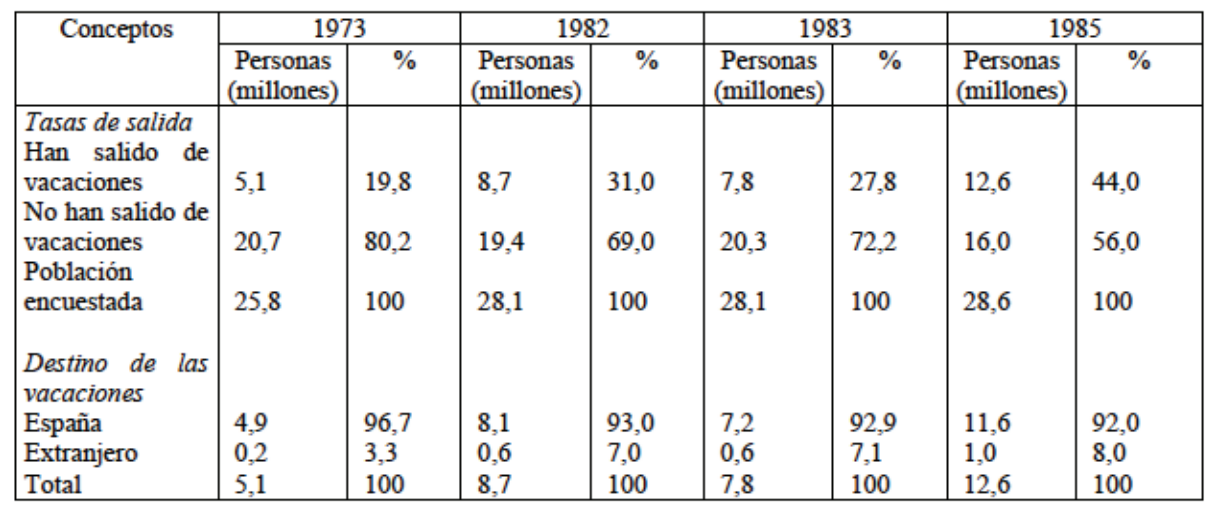

\begin{tabular}{|c|c|c|c|c|c|c|c|c|}
\hline \multirow[t]{2}{*}{ Conceptos } & \multicolumn{2}{|c|}{1987} & \multicolumn{2}{|c|}{1990} & \multicolumn{2}{|c|}{1992} & \multicolumn{2}{|c|}{1995} \\
\hline & $\begin{array}{l}\text { Personas } \\
\text { (millones) }\end{array}$ & $\%$ & $\begin{array}{l}\text { Personas } \\
\text { (millones) }\end{array}$ & $\%$ & $\begin{array}{c}\text { Personas } \\
\text { (millones) }\end{array}$ & $\%$ & $\begin{array}{l}\text { Personas } \\
\text { (millones) }\end{array}$ & $\%$ \\
\hline Tasas de salida & & & & & & & & \\
\hline $\begin{array}{l}\text { Han salido de } \\
\text { vacaciones } \\
\text { No han salido de }\end{array}$ & 9,5 & 45,0 & 16,4 & 43,4 & 11,6 & 44,5 & 18,1 & 58,4 \\
\hline $\begin{array}{l}\text { vacaciones } \\
\text { Población }\end{array}$ & 11,6 & 55,0 & 14,4 & 46,6 & 14,5 & 55,5 & 12,9 & 41,6 \\
\hline encuestada & 21,1 & 100 & 30,8 & 100 & 26,1 & 100 & 31,0 & 100 \\
\hline $\begin{array}{l}\text { Destino de las } \\
\text { vacaciones }\end{array}$ & & & & & & & & \\
\hline España & 8,2 & 87,0 & 13,3 & 81,0 & 10,0 & 86,4 & $41,8^{*}$ & 92,1 \\
\hline Extranjero & 1,3 & 13,0 & 3,1 & 19,0 & 1,6 & 13,6 & $3,6^{*}$ & 6,9 \\
\hline Total & 9,5 & 100 & 16,4 & 100 & 100 & 100 & $45,4^{*}$ & 100 \\
\hline
\end{tabular}

*Número de viajes

Cuadro 4. Las vacaciones de los españoles entre 1973 y 1995: tasas de salida y destinos.

Fuente: BOTE, Venancio; MARCHEANA, Manuel y SANTOS, Enrique: "La descentralización autonómica y la diversificación de la estrategia de desarrollo turístico (1974-1998)", en Carmelo PELLEJERO (dir.) Historia de la economía del turismo en España, Civitas, Madrid, p. 145.

63 VALLEJO, Rafael: "Economía e historia del turismo...”, pp. 207-208.

64 BOTE, Venancio; MARCHEANA, Manuel y SANTOS, Enrique: "La descentralización autonómica y la diversificación de la estrategia de desarrollo turístico (1974-1998)", en Carmelo PELLEJERO (dir.) Historia de la economía del turismo en España, Civitas, Madrid, p. 144. 
Los datos no dejan de ser significativos, hasta tal punto que se ha producido una re-valorización de la demanda turística nacional interna en las décadas finales del siglo XX, debido al mayor nivel de vida de los españoles. De ahí que las vacaciones de éstos en el interior del país ya no puedan limitarse a ser un mero complemento de la demanda turística internacional. De hecho, es factible hablar de nuevas funciones, tales como su contribución a paliar una posible disminución de la demanda exterior, a compensar la estacionalidad de la demanda (centrada en los meses de verano) o a constituirse en una importante aportación al desarrollo regional y local ${ }^{65}$.

Con todo, y a pesar de esta especialización de España en turismo de sol y playa y los buenos resultados que produce, lo cierto es que en los últimos años se está produciendo una evolución del turismo de masas hacia una nueva diversificación y una mayor calidad en los servicios y el medio urbano y natural que sirve de soporte físico a la actividad turística. Con la peculiaridad de que ahora son unas masas más educadas y con mayor conciencia ecológica las que solicitan esa excelencia. Estaríamos posiblemente ante la emergencia de un nuevo paradigma que se ha dado en llamar Nueva Era del Turismo, que induce a los oferentes a internalizar los efectos externos de la actividad turística, a integrar el medio ambiente como parte de la oferta turística y a incorporar la calidad ecológica y urbana entre los objetivos de la política turística ${ }^{66}$.

\section{Conclusiones}

Tal como se ha podido apreciar en este artículo, el turismo de ola ha jugado un papel de especial importancia dentro de la historia turística de España. Si bien es verdad que sus antecedentes se remontan al siglo XIX, lo cierto es que fue en la siguiente centuria cuando fue tomando auténtica carta de naturaleza. Así, y tal y como sucedió en el resto del continente europeo, si en las primeras décadas del siglo XX las playas frías de la fachada atlántica seguían siendo las más demandadas en verano por un turismo todavía marcado por la distinción, a partir de la Segunda Guerra Mundial los cambios que se produjeron en los flujos turísticos fueron trascendentales para el devenir de esta actividad. Por un lado, la crisis del paradigma higienista, la práctica de nuevos deportes como la natación, la moda de broncearse y la sucesión de un nuevo paradigma pusieron en valor unas playas templadas hasta hacía poco sólo frecuentadas en invierno. Por otro, esa edad dorada que vivieron las economías de la Europa occidental en la década de los cincuenta, y, sobre todo, en los sesenta, dieron como resultado una democratización del turismo. Semejante bonanza económica permitió a un gran número de europeos, y de españoles después, disponer de tiempo libre y recursos (días de vacaciones retribuidos) para poderse desplazar a otros lugares. De manera que ese descubrimiento del Mediterráneo de unos pocos privilegiados en el periodo de entreguerras se extendió a capas cada vez más amplias de la población. El sol de España hizo furor, convirtiéndose este país en uno de los destinos más de-

65 BOTE, Venancio; MARCHEANA, Manuel y SANTOS, Enrique: "La descentralización autonómica..., pp. $147-148$

66 VALLEJO, Rafael: “Economía e historia del turismo...”, p. 205. 
mandados por los visitantes del norte y del centro de Europa. En el lapso de tiempo de unas pocas décadas las cifras de turistas se multiplicaron, contribuyendo así el turismo, básicamente de playa, no sólo a compensar una buena parte del valor de las importaciones, sino también al propio PIB en cifras nada desdeñables (alcanzado casi el $12 \%$ en la actualidad). En definitiva, en cincuenta años España se ha convertido en una de las principales potencias turísticas mundiales gracias al turismo de sol y playa y a la popularización de esta actividad entre sectores cada vez más amplios de la sociedad, partiendo de una posición claramente rezagada a principios del siglo XX. 